\section{$\underset{\substack{\text { hommes } \\ \text { \& migrations }}}{ }$}

\section{Hommes \& migrations}

Revue française de référence sur les dynamiques

migratoires

$1282 \mid 2009$

Santé et droits des étrangers : réalités et enjeux

\title{
Duong Thu Huong, Au zénith
}

Traduit du vietnamien par Phuong Dang Tran. Édition Sabine Wespieser 2009, 787 pages, 29 euros

\section{Mustapha Harzoune}

\section{(2) OpenEdition}

\section{Journals}

Édition électronique

URL : http://journals.openedition.org/hommesmigrations/483

DOI : 10.4000/hommesmigrations.483

ISSN : 2262-3353

Éditeur

Musée national de l'histoire de l'immigration

Édition imprimée

Date de publication : 1 novembre 2009

Pagination : 208-209

ISSN : 1142-852X

Référence électronique

Mustapha Harzoune, "Duong Thu Huong, Au zénith », Hommes \& migrations [En ligne], 1282 | 2009, mis en ligne le 29 mai 2013, consulté le 22 septembre 2020. URL : http://journals.openedition.org/ hommesmigrations/483; DOI : https://doi.org/10.4000/hommesmigrations.483

Ce document a été généré automatiquement le 22 septembre 2020.

Tous droits réservés 


\section{Duong Thu Huong, Au zénith}

Traduit du vietnamien par Phuong Dang Tran. Édition Sabine Wespieser 2009, 787 pages, 29 euros

\section{Mustapha Harzoune}

\section{RÉFÉRENCE}

Duong Thu Huong, Au zénith, Traduit du vietnamien par Phuong Dang Tran. Édition Sabine Wespieser 2009, 787 pages, 29 euros

1 Bien sûr, ce n'est pas l'essentiel du propos de Duong Thu Huong, mais ce récit, consacré aux dernières journées du "Président", Ho Chi Minh, et à un implacable examen de conscience, parle aussi de l'exil parisien du père de l'indépendance vietnamienne. "J'ai cherché pour mon peuple un Paris chaleureux et j'ai trouvé un Moscou glacial [...]. La France de Diderot et de Voltaire m'a ouvert ses portes puis l'autre France, celle des képis et des uniformes, me l'a refermée au nez comme un valet aurait claqué la porte d'un château devant un mendiant [...]", dit le Président entre deux évocations nostalgiques de sa période parisienne.

Le Président est seul. Trahi par ses anciens compagnons de combat. À l'exception de Trân $\mathrm{Vu}$, décrit comme "un homme droit, entier, qui ne se permet jamais d'être étreint par des sentiments qu'il juge médiocres d'après son code moral".

3 "C'est bégayer qu'il faut, au trébuchet de l'âme", dit le poète Abû Nuwâs. Face au "tribunal de sa conscience", "Le Président" ne bégaie pas. Il reste sans voix; écrasé par la honte et la culpabilité. Double. Coupable pour avoir trahi la femme qu'il aimait et abandonné ses enfants. Coupable pour avoir conduit son peuple à la ruine et à la dictature. Les apparitions du président Man (Mao), pour qui "le pouvoir ne peut tolérer les sentiments humains", confrontent deux hommes et deux logiques politiques. Pour le Grand Timonier, Ho Chi Minh serait devenu le "bon disciple de l'occident" : acculturé,

4 il en aurait oublié les règles et les mentalités de ses frères indigènes. Il serait, comme on dit aujourd'hui, une "banane" : jaune à l'extérieur mais blanc à l'intérieur... 
Duong Thu Huong est connu pour son combat en faveur de la liberté dans son pays. Au Zénith ne déroge pas à cette thématique : dénoncer avec force ce que les communistes ont fait du Vietnam, une société plus inhumaine encore aujourd'hui qu'hier, et ce en convoquant à ses côtés le primus inter pares. Mais cela serait trahir l'œuvre de cette femme que de réduire ce roman à un pamphlet. Duong Thu Huong est une conteuse hors pair, une romancière qui tisse et entrelace les histoires et les parcours, une écrivaine qui mêle le conte, le récit historique, la sagesse populaire, la langue classique mais aussi celle, plus verte et crue, du peuple.

6 Duong Thu Huong montre la profondeur et la diversité - culturelle, historique, humaine de son pays. Elle s'applique à distinguer ville et campagne, modernité et tradition, et surtout cultures ancestrales - paysanne ou bouddhique - et nouvelles règles qui corsètent un peuple et son pays.

Plusieurs fils narratifs forment le tissu de ce vaste roman : l'introspection du Président, l'histoire de Quang, de son amour et de sa fidélité à Ngân, malgré la jalousie de son fils aîné. Quang est pour "Le Président" un "miroir" qui le renvoie devant sa conscience tourmentée non seulement par l'abandon de Xuân, la femme qu'il aimait, mais aussi par sa passivité quand certains responsables du parti, qu'il a lui-même crée, décidèrent de l'assassiner. Trois hommes restituent cette tragique histoire: "Le Président", Vu, l'ami fidèle, qui prendra soin des deux enfants du "grand frère" et le "compatriote inconnu", le beau-frère de Xuân qui a juré de la venger.

Duong Thu Huong n'est pas tendre pour les siens quand elle évoque les mentalités paysannes et les "vices" de son peuple, à commencer par le premier d'entre eux, la jalousie: "le sentiment traditionnel du peuple vietnamien". "Du point de vue sociologique, la Révolution a fait remonter la vase à la surface de l'eau", écrit l'auteure. Mais, a contrario, elle loue la sagesse populaire, ces "valeurs culturelles populaires" détruites par le nouveau régime. Une destruction qui a conduit au fiasco.

9 Malgré le thème de l'amour, omniprésent chez Duong Thu Huong, Au Zénith est une sombre réflexion sur l'âme humaine, l'envie, la jalousie, le pouvoir, sur le temps qui “ transforme tout en illusion", en "pourriture"!

Le Président décide de mourir le 2 septembre 1969 comme un présage... pour mettre "fin à ce régime traitre et cruel" et exterminer "les démons qui sucent le sang du peuple". 